San Jose State University

SJSU ScholarWorks

Master's Theses

Master's Theses and Graduate Research

Fall 2020

\title{
Greenhouse Gas Emissions From Lithium-Ion Batteries Operating In California's Electrical Grid In 2019
}

Peter J. Hilkene

San Jose State University

Follow this and additional works at: https://scholarworks.sjsu.edu/etd_theses

\section{Recommended Citation}

Hilkene, Peter J., "Greenhouse Gas Emissions From Lithium-Ion Batteries Operating In California's Electrical Grid In 2019" (2020). Master's Theses. 5145.

DOI: https://doi.org/10.31979/etd.vuv6-tnxt

https://scholarworks.sjsu.edu/etd_theses/5145

This Thesis is brought to you for free and open access by the Master's Theses and Graduate Research at SJSU ScholarWorks. It has been accepted for inclusion in Master's Theses by an authorized administrator of SJSU ScholarWorks. For more information, please contact scholarworks@sjsu.edu. 


\title{
GREENHOUSE GAS EMISSIONS FROM LITHIUM-ION BATTERIES OPERATING
}

IN CALIFORNIA'S ELECTRICAL GRID IN 2019

\author{
A Thesis \\ Presented to \\ The Faculty of the Department of Environmental Studies \\ San Jose State University \\ In Partial Fulfillment \\ of the Requirements for the Degree \\ Master of Science
}

by

Peter Hilkene

December 2020 
(C) 2020

Peter Hilkene

ALL RIGHTS RESERVED 
The Designated Thesis Committee Approves the Thesis Titled

\author{
GREENHOUSE GAS EMISSIONS FROM LITHIUM-ION BATTERIES OPERATING \\ IN CALIFORNIA'S ELECTRICAL GRID \\ by \\ Peter Hilkene
}

APPROVED FOR THE DEPARTMENT OF ENVIRONMENTAL STUDIES

SAN JOSÉ STATE UNIVERSITY

December 2020

Dustin Mulvaney Ph.D. Department of Environmental Studies

Lena Perkins Ph.D. $\quad$ City of Palo Alto

Benoit Delaveau M.S. Department of Environmental Studies 


\title{
ABSTRACT \\ GREENHOUSE GAS EMISSIONS FROM LITHIUM-ION BATTERIES OPERATING IN CALIFORNIA'S ELECTRICAL GRID
}

\author{
by Peter Hilkene
}

This work examines the impact on greenhouse gas emissions of energy storage devices operating on the California electrical grid during the year 2019. As solar power gains a greater share in California's energy production, tools for storing the intermittent energy produced from solar and other variable generation sources become important in continuing their growth. In this study, the impact of the deployment of energy storage capacity in California was determined using three charging and discharging strategies. The first, meeting peak net-demand with solar, looked at battery charging when solar production was highest and discharging when net-demand is highest. The second used an energy arbitrage strategy that responds to the average price of energy, maximizing profitability. The third strategy examined maximizing emissions reductions using Watttime's marginal emissions factors (MEF). Each of these operation patterns use MEFs to determine their impact on greenhouse gas emissions and use average pricing data for all locational nodes in California to determine the profitability of operating with a $1 \mathrm{MWh}$ change in energy storage capacity. The results show that the deployment of Lithium-Ion batteries can result in a reduction in carbon emissions at a low cost, highlighting the importance of curtailment alleviation to beneficial energy storage device operation. 


\section{ACKNOWLEDMENTS}

I would like to thank those around me who have been so supportive throughout this whole process. My parents Nicky and Martin and girlfriend Amanda who listened to me talk about batteries and offering encouragement throughout the process. Over the two and a half years at San Jose State their support has been integral in getting me to this point. I also want to thank my committee members and especially my committee chair Dr. Mulvaney who guided me through this process and opened up additional opportunities that have made my experience at SJSU significantly more valuable. I also want to acknowledge the role Watttime played in this project, supplying me with a source of historical Marginal Emissions data that allowed this study to be conducted more accurately. 


\section{TABLE OF CONTENTS}

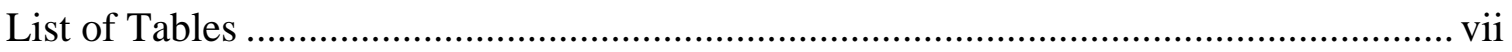

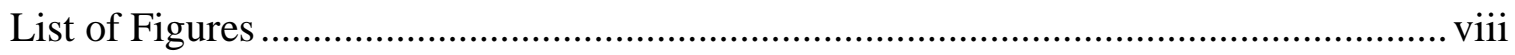

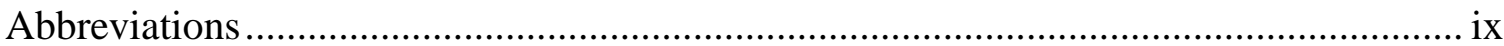

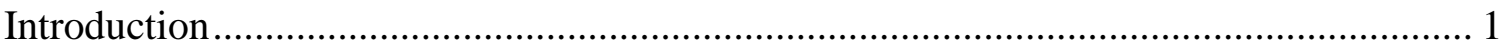

Motivation and Scope .................................................................................... 1

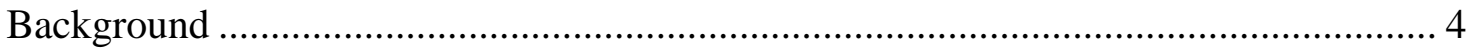

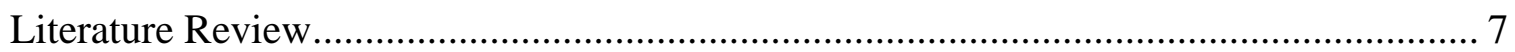

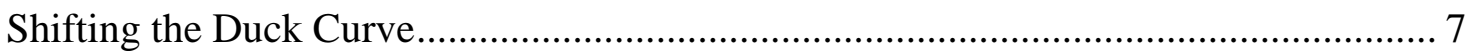

Greenhouse Gas Emissions from Storing Energy ……….......................................... 12

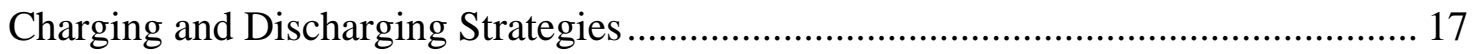

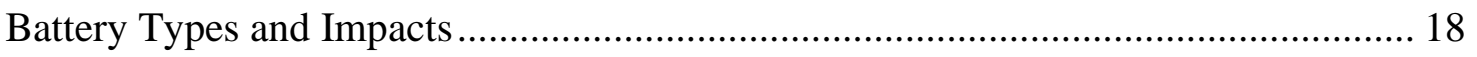

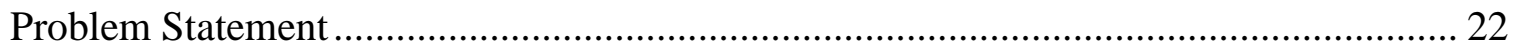

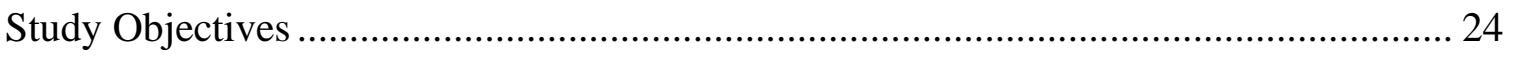

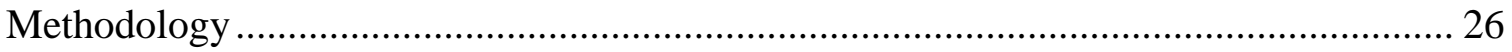

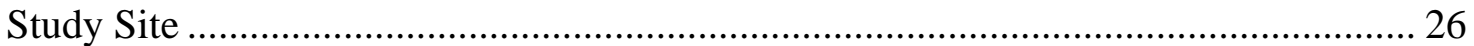

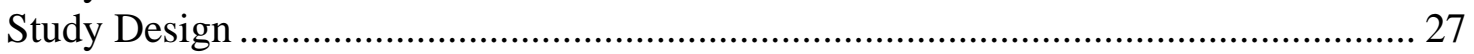

Hours of Operation/ Use Strategies........................................................................... 29

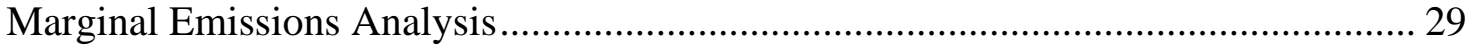

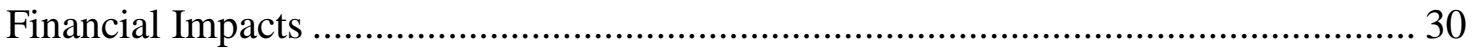

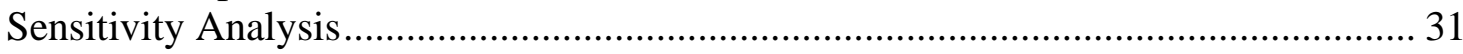

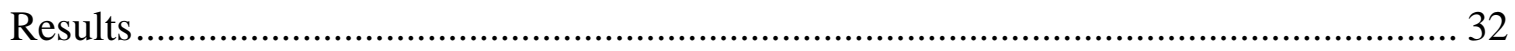

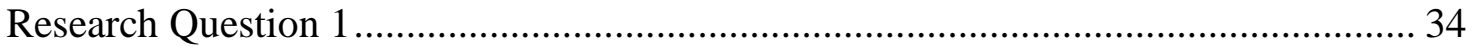

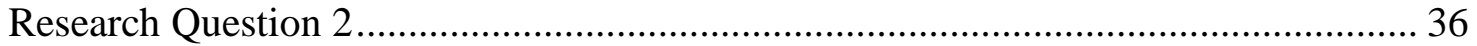

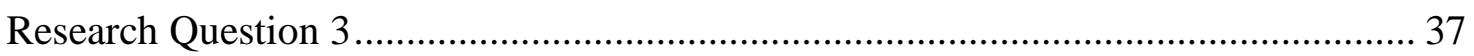

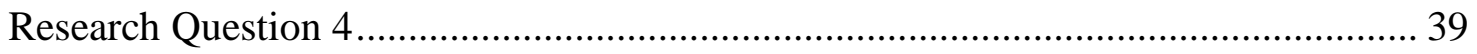

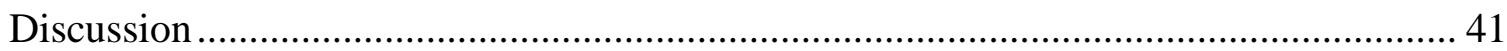

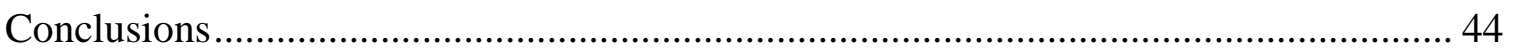

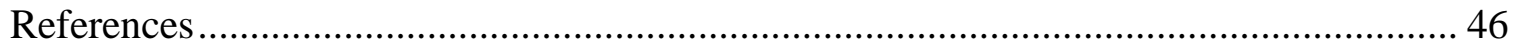




\section{List of Tables}

Table 1. Average Impact Per Wh by Li-ion Battery Chemistry Type............. 20

Table 2. Impact by Operation Profile with and Without Curtailment 90\% RTE...... 33

Table 3. Impacts of Operating 1MWh of Energy Storage at 90\% RTE Energy and the Cost per Unit of Emission Reduction for Each Strategy ........... 40 


\section{List of Figures}

Figure 1. California duck curve representing net demand change as a result of increased solar penetration.....................................

Figure 2. Change in emissions by round trip efficiency for the optimized emissions operation pattern both with curtailment alleviation and

Figure 3. Change in emissions by round trip efficiency for the solar to meet peak net-demand operation pattern both with curtailment alleviation and without.........................................................

Figure 4. Change in emissions by round trip efficiency for the energy arbitrage operation pattern both with curtailment alleviation and without. 


\section{Abbreviations}

$\mathrm{EV}$ - Electric Vehicle

GHG - Greenhouse Gas

LCO - Lithium Cobalt Oxide

LCOE - Levelized Cost of Energy

LFP — Lithium Iron Phosphate

LFP-LTO - Lithium Iron Phosphate-Lithium Titanate

Li-ion - Lithium Ion

LMO - Lithium Manganese Oxide

MEF - Marginal Emissions Factor

NCM - Nickel Manganese Cobalt

NCA - Nickel Cobalt Aluminum

RTE - Round Trip Efficiency

VG - Variable Generation 


\section{Introduction}

\section{Motivation and Scope}

Climate change and the need to rapidly decarbonize the world's energy and transportation systems are widely accepted realities (IPCC special report, 2018). To date, the process of developing renewable energy sources and its adjacent technology in a way that maximizes environmental benefits is understudied. The positive perception of renewable energy by many proponents of climate action can lead to overlooking potential negative impacts that can occur across the life cycle of green technology devices. Technologies like solar photovoltaics, wind turbines, and batteries are valued for their low carbon attributes and potential applications that will help to address and alleviate the many environmental issues caused by fossil fuel energy generation sources. This can lead to decisions to deploy green technology without adequate consideration of their impacts leading to the inefficient allocation of resources and unintended negative consequences. In the case of increasing energy storage capacity, a well-intentioned push to utilize this technology to support the growth of renewable energy could result in an unintended increase in greenhouse gas (GHG) emissions due to energy losses if not designed with these considerations in mind. The deployment of energy storage devices needs to be done in a considered manner, establishing a growth rate that accommodates the growing solar energy production capacity without overcommitting resources. Recycling programs will also be key for ensuring future resource availability and minimize the end-of-life impacts of battery storage devices. Without such programs and considerations, the availability of key resources in the future could be jeopardized. The expansion of renewable energy 
contributions to the grid could be slowed as the amount of demand available to be met by these sources decreases, and wasted energy generation from curtailment increases ultimately reducing the ability of these generation sources to be financially viable.

The demand created by the ongoing push to increase energy storage capacity in California is likely to be met largely by Lithium-ion ( $\mathrm{Li}$-ion) batteries due to their high efficiency and relative low cost. One of the more concerning issues associated with the production of these batteries is the impactful sources key elements are often drawn from for production. The status of these resources as "critical raw materials," and "technologically critical elements" means that along with the environmental and sociological impacts of harvesting, key elements in Li-ion batteries also face the risk of supply shortage and price volatility (EU commission, 2017). An example is cobalt, commonly used as cathode material in Li-ion batteries and primarily harvested from the Democratic Republic of the Congo with roughly 64\% of the world's production in 2018 (USGS, 2019). The Democratic Republic of Congo has inadequate labor and environmental protections that can make practices like small scale artisanal mining damaging: without adequate controls in place the extraction of cobalt can result in unhealthy exposure to toxic substances for workers and the surrounding environment. In Burkina Faso, the Tambao manganese mines, home to the majority of the world's manganese, has been the subject of major disputes with the Pan African Minerals Group, over who has control over the mine. The case of Pan African Minerals Group vs. Burkina Faso ruled in favor of Burkina Faso allowing them to retain control over the mines (Ndiaga \& Rumney, 2019). Chile, a large producer of lithium, has struggled with the 
extraction process for this material, which requires a large amount of water usage in predominately desert areas (Sherwood, 2018). Water depletion on such a scale has left places like the Atacama Desert in Chile with a landscape of salt flats where meadows and lagoons once flourished.

With the potential demand for Li-ion batteries expected to increase as energy storage deployment accelerates, the demand for these scarce and often irresponsibly sourced materials will likely increase as well. Additionally, unless adequate preparations are made batteries at their end-of-life could overwhelm existing recycling capabilities. With the ongoing growth of demand for electric vehicles (EVs) along with Li-ion battery use in everyday electronics like cell phones and laptops, demand for Li-ion batteries is high. There is reason for concern over the future availability of the reserves of important Li-ion materials that could slow or limit the use of energy storage and subsequently the growth of renewable energy (West, 2017). Issues like these will only be exacerbated by the increased demand for batteries and as such should be cause for serious consideration of whether now is the right time to push for increased battery storage on California's electrical grid. For the purpose of this study, the effects of resource extraction, and the production of energy storage devices were not examined. Instead, the end-use impacts were the focus, specifically the impact on GHG emissions and the profitability from the storage devices operation. This approach is motivated by an interest in understanding the different GHG impacts from various operation profiles for energy storage and power generation in California and to better understand what efficient emission-reducing usage of energy storage would look like. 


\section{Background}

Storing energy provides valuable electrical grid services, like frequency regulation, ramping, load following, and voltage support. However, the current push to deploy greater energy storage capacity is fueled by California's desire to aid in the development of carbon-free energy sources (CA energy storage roadmap, 2014). The use of renewable energy has been growing rapidly in the state of California, posing new challenges to the state's grid operators. The overgeneration of energy is becoming more common in California as a result of increasing amounts of mid-day demand being met by solar power. To address the excess energy generation, electrical grid operators curtail renewable energy sources like wind and solar, reducing the amount of energy these sources provide to the electrical grid. These types of generation sources are chosen for curtailment because of their ability to power up or down without the need for resource consumption. Other generation sources such as natural gas power plants would have to spend time ramping down if curtailed, consuming fuel during that period making it the more costly option for curtailment. At times the price of energy can drop below $\$ 0$, requiring California to pay other states to take and use its excess energy (Luoma, Mathiesen, \& Kleissl, 2014). Unless actions are taken to shift demand for electricity from peak times to times where curtailment is probable, the frequency of negative net loads is projected to continue to increase. This occurs when variable generation $(\mathrm{VG})$ sources such as solar or wind supply more power than the total demand for energy, removing any need for traditional non-variable sources, such as hydroelectric or natural gas, to meet the energy demand (Shaker, Zareipour, \& Wood, 2016). The increasing frequency of 
curtailment events and negative net loads will cause the value of energy produced by new and existing renewable energy projects to drop, reducing their ability to displace energy generation from GHG intensive sources. Offering storage as an alternative option to curtailing would not only increase the amount of renewable energy used to meet the state's demand but would also increase the financial viability of using renewable energy sources by preventing energy waste and increasing its value by using it when there is higher demand (Hill, Such, Chen, Gonzalez, \& Grady, 2012). The alternative is to continue to overbuild the state's solar energy generating capacity, making each additional unit less effective while doing so. This would also increase the number of resources needed to produce solar photovoltaics and contribute to greater land-use impacts that typically occurs with solar power projects.

The process of storing energy comes with inherent inefficiencies due to energy loss. The percentage of energy put into a storage device that is available for use when discharging is referred to as the round-trip efficiency (RTE). Due to this energy inefficiency, the operation of an energy storage device when not used to alleviate curtailment creates an increase in the total demand for energy generation. When a device is being charged the energy entering it is no longer able to meet the energy demand at that time, necessitating an increase in energy generation to supplement what is available thereby causing an increase in GHG emissions at that time. Therefore, during the discharging of stored energy demand is displaced by the energy being supplied by the energy storage device causing other energy sources that would have otherwise have been operating to reduce the amount of energy they are generating. The amount of energy 
displaced by discharging is less than the increase in generation caused by the charging of the storage device due to the energy losses that occur during the storing process. However, not all energy used to charge the storage device is available to be discharged due to the inherent energy losses associated with the storage process. The RTE for Li-ion batteries is dependent on the chemistry used and can vary between around $85 \%$ to $95 \%$ (Zablocki, 2019). Due to the inefficiency and subsequent increase in total demand for energy, the operation of Li-ion batteries can easily increase GHG emissions. The impact that energy storage operation implemented in California may have on GHG emissions is not fully understood yet. The impact is dependent on the round-trip efficiency and carbon intensity of the energy source replacing or being displaced by the change in demand caused by the operation of the storage device. The carbon intensity of these sources is represented by the marginal emissions factor (MEF) which is the change in emissions from adding or removing a unit of demand for energy generation at a given time. The MEF varies depending on the level of demand, sources used to supply the demand and the regional variations that dictate what source or type of source would power up or down in response to a change in demand. 


\section{Literature Review}

\section{Shifting the Duck Curve}

As solar energy penetration in the California electrical grid continues to increase, new issues have begun to arise with managing this often-unpredictable resources. The duck curve is a plot of net demand for energy, or demand for energy without variable generation (VG) sources, like wind and solar, on a spring day in California. The curve shows a dip in net demand during the hours solar energy is produced, followed by a steep upward slope towards the peak net demand as solar resources slow to a halt (Roberts, 2018). The graph is referred to as the duck curve because of the deep "belly" and raised peak or "head" that resemble a duck floating on water. Figure 1 below shows the netdemand on April 21, 2019, that exemplifies this phenomenon, there was a larger amount of renewable energy curtailment in the middle of the day and the price of electricity went negative during that time.

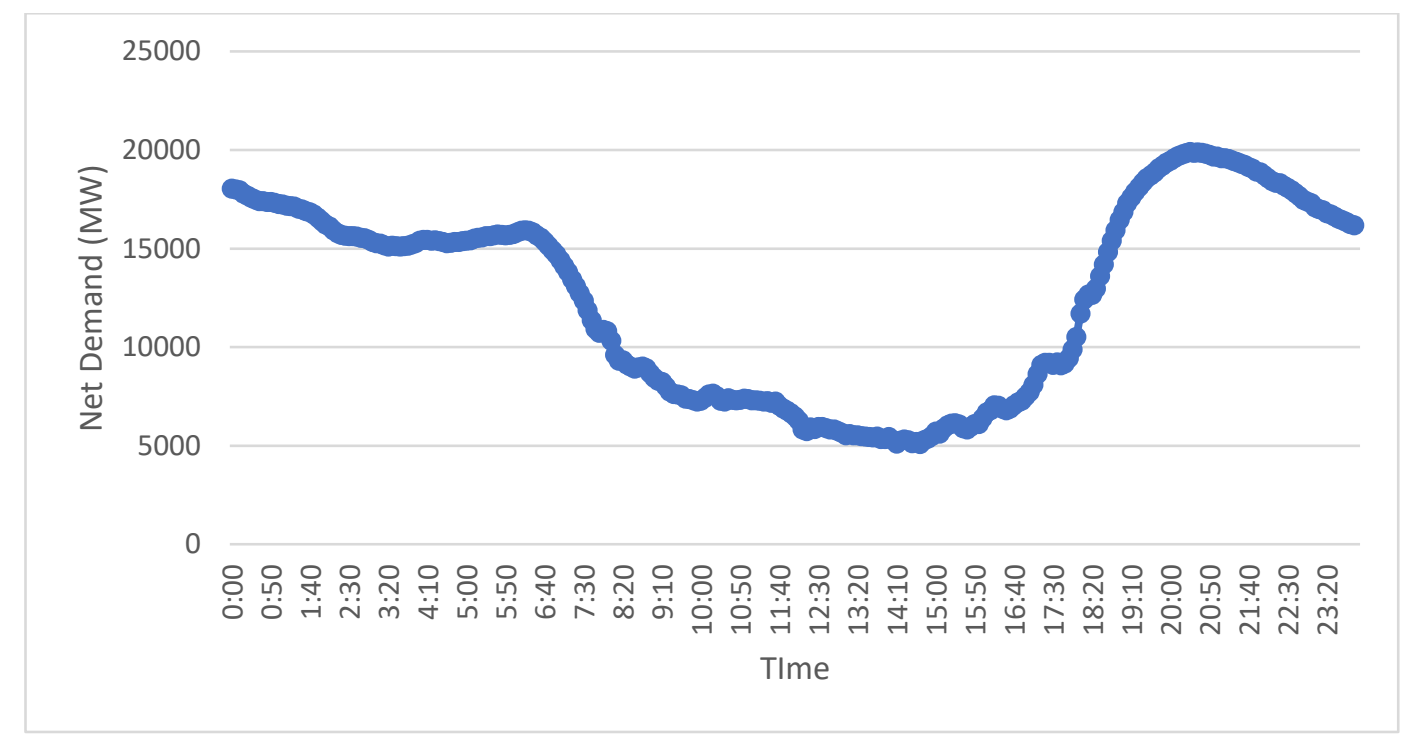

Figure 1: California duck curve representing net demand change as a result of increased solar penetration, Data published by CAISO. 
Despite its fun name, the duck curve indicates significant challenges with the curtailment of renewable energy and increased requirements for evening energy ramping to meet peak demand. If unaddressed, the deepening duck curve will decelerate the growth of solar photovoltaics, potentially causing solar power generation to reach a plateau as a result of financial opportunity loss from curtailment and lower daytime energy prices. Energy storage has the potential to play a role in preventing this from happening by storing energy during periods of high solar power production and alleviating curtailment, ultimately allowing new solar projects to be more financially viable. It is projected that solar plus storage projects will make up 55\% of all energy storage deployed by 2023 (Gupta, 2019). A study done by the National Renewable Energy Laboratory determined the quantity of energy storage capacity necessary to allow solar power to provide 50\% of California's energy (Denholm \& Margolis, 2016). Using data on existing grid conditions within the state, the study projected future scenarios with varying degrees of flexibility and determined how much solar growth could occur with the addition of different amounts of storage. Specifically, the study focused on keeping the cost of solar plus storage at or below market energy prices for energy while maximizing the growth of solar energy under different degrees of grid flexibility. The results showed that for solar to be capable of meeting half of California's demand, a total of $19 \mathrm{GW}$ of energy storage would be needed, assuming a low cost of photovoltaics, the ability to turn off all thermal generation, and other practices that increase grid flexibility. For a comparison, in 2019 12.28\% of California's demand for energy was met by solar power sources (Nyberg, 2019) 
There are two categories that the strategies for addressing the issue of overgeneration and subsequent curtailment of renewables can fall into. These are either fattening the duck, also referred to as over-building, or teaching the duck to fly, which is another way to say flattening the curve. Fattening the duck strategies involve increasing the flexibility of the grid to allow for greater daytime solar penetration. Such strategies typically involve changing operational practices to allow for more cycling, unit starts, demand response such as for smart-charging EVs, and stopping and/or minimizing the number of units operating at partial load. In California some power generators using traditional fuel sources have must-run contracts that allow them to run without curtailment to ensure local grid reliability (Golden \& Paulos, 2015). By improving the ability of non-VG power sources to adjust to grid conditions, decreasing and increasing power production with demand can be done to accommodate greater amounts of solar power generation. To a greater degree renewable energy sources experience less curtailment as the amount of solar power that can be used during the day increases and improve the financial viability of future projects. Flattening the duck, or teaching the duck to fly is another group of strategies that involves moving net demand from peak hours to off-peak hours. Flattening the duck can be achieved either through finding new sources of carbon-free energy generation, decreasing energy consumption, improving energy efficiency at peak hours, or storing energy produced during off-peak hours for use during peak demand (Lazar, 2016). For this study, I focused on the last of these strategies and the impacts of using Liion battery technologies to shift energy demand from peak hours to the daytime hours when there is a dip in net demand. By shifting the energy demand away from off-peak 
hours, the flexibility for energy production would allow curtailment to be minimized (Denholm et. al, 2015).

As California attempts to reach its goals for decarbonizing its electrical grid, energy storage is expected to be a key player both in the short term and long term (CAISO, 2014). By shifting demand and curtailment alleviation in the short term and covering seasonal variation and ensuring power reliability in the long term (Gallo, SimõesMoreira, Costa, Santos, \& Dos Santos, 2016) renewable penetration increases. Utilizing both of these, a future where all energy generation comes from carbon free sources can become possible.

When using batteries to flatten the duck curve the storage duration, or length of time a battery is charging/discharging matters. Storage duration from two to eight hours were studied while taking into account the solar photovoltaics and the shape of the peak in net demand to determine which storage duration is best Denholm and Margolis (2018) examined the limitations and economic impact of using different combinations of energy storage discharge lengths to replace natural gas peaker plants. The study also paid close attention to the impact of four-hour energy storage due to California's Public Utility Commission's four-hour rule which sets the target for discharge time at four hours. The results of the study varied depending on the level of solar penetration but they ultimately showed the need to grow and adapt the energy storage capacity to grid conditions as renewable energy portfolios grow.

The end goal of both types of strategies for addressing the duck curve is to allow solar power to meet a greater portion of the demand for energy from the state's electrical grid. 
To achieve this, new solar projects need to be financially viable which requires minimizing curtailment along with preventing value deflation due to low net-demand for energy during solar energy-producing times (Mulvaney, 2019). To reach 50\% solar penetration adequate grid flexibility is needed to minimize the cost of solar projects by decreasing the need for energy storage which raises the costs of the solar project (Denholm, Margolis, 2016). Going forward the levelized cost of electricity (LCOE) from solar can be expected to continue to decrease as panels get more efficient and cheaper to make. However, using the LCOE of solar alone is not sufficient for determining the viability of a solar project. With the time of use energy rates in place, hours of off-peak demand can experience low energy costs. These energy prices can be lower than the LCOE of solar meaning that despite a lower LCOE for solar than a natural gas turbine, the turbine can still be the most financially viable option due to its ability to produce power during peak demand (Branker, Pathak, \& Pearce, 2011). Ideally, the amount of storage utilized to increase penetration of solar would be minimized due to the additional cost of the storage device and the power lost through inefficiencies, which would in turn reduce the LCOE of solar plus storage projects. Under the right conditions, solar plus storage can increase the value of a project if the right amount of storage to energy generation capacity is installed with adequate grid conditions (Denholm, Margolis, \& Eichman, 2017). Additionally, determining the impact on emissions that results from the addition of storage to renewable energy can be found by looking at the difference in MEFs between the periods that renewable sources produce energy and discharge times. 


\section{Greenhouse Gas Emissions from Storing Energy}

Energy generation from traditional energy sources such as natural gas, coal, and petroleum creates atmospheric emissions of various pollutants, many of which fall into the category of GHGs and other pollutants that pose a direct threat to human health and the health of the surrounding biosphere. Negative environmental impacts exist throughout the life cycle of fossil fuels from extraction to energy generation to waste by products: from fuel spills that occur during transport; groundwater contamination; fugitive methane emissions from fracking; acid rain that results primarily from the emission of SO 2 which react with moisture in the air to form sulfuric acid; tropospheric ozone, or smog, that occurs when NO X emissions react with sunlight and hydrocarbons. These are just a few of the environmental challenges we face due to our reliance on fossil fuels for energy

production and transportation. Renewable energy and its adjacent technologies also come with negative environmental impacts, especially if the technologies are mismanaged. Energy storage has been shown to increase GHG emissions as a result of the inherent inefficiencies of energy storage. Due to energy loss during the storage process, the total demand for energy has to increase as the energy lost can no longer be used to meet the demand. Instead, there must be an increase in generation from an adjustable source, typically natural gas or imported energy in the case of California. Research on the effect energy storage connected to an electrical grid has on GHG emissions is incomplete, due to the many ways studies can model energy storage devices operations, and the many factors that can influence the MEFs. 
A study conducted in Texas looked at the financial and environmental effects of using behind-the-meter energy storage to reduce reliance on the utility. Using data on household energy use and solar production gathered from a public database, as well as electricity tariffs from Texas, California, and Hawaii for market energy cost data. The study looked at the economic and environmental costs of the batteries' operation. Ultimately the study found that behind-the-meter applications of battery storage would increase emissions of GHG's due to the resulting increase in generation from coalpowered energy sources and minimal to non-existent renewable curtailment alleviation (Webber \& Fares, 2017).

In a different study, the effect of large-scale energy storage on emissions was looked at with an energy arbitrage strategy that attempts to charge/discharge the device to maximize profitability. In this strategy, energy would be stored at the hour with the lowest price of energy, which was in the middle of the night, and sold when the price was highest in the late afternoon and early evening. The study used pricing and emissions data from 20 eGrid regions in the U.S. to estimate the impact on emissions that an energy arbitrage strategy would have. It found that for each region, emissions for RTEs of 95\% and under would increase, with California projected to experience a relatively small increase under most scenarios modeled (Hittenger \& Azevedo, 2015). Energy arbitrage often results in the battery charging in the middle of the night when demand is low. On an electrical grid with large amounts of solar energy, overnight charging breaks the first rule of operating a storage device in a green manner, "charge clean and displace dirty" (Arbabzadeh, Johnson, Keoleian, Rasmussen, \& Thompson, 2016). A third study that 
looked at the impact of operating an energy storage device on GHG emissions did not take into account roundtrip energy losses making it unreliable for real-world applications. Instead, the study is used to drive home the point that green operation of a battery would require charging from a "cleaner" source than the one being displaced. Taken together, these studies underscore that under most existing conditions energy arbitrage results in undesirable increases in GHG emissions.

The GHG emissions profile of energy storage is dependent on the mix of grid electricity when the device is charging or discharging. One factor with significant influence over operating times is the pricing structure for energy. One study looks at the impact of pricing on New England ISO data from the previous five years (Griffiths, 2019). Using hourly emissions factors and a multitude of rate structures with both seasonal and hourly differences, the study models the behavior of behind-the-meter storage devices used to supply power for various building types. The results show how rate structures can significantly impact the effect of storage on GHG emissions. The authors further noted that as grids integrate more renewable energy, the issue of increasing emissions becomes less prominent. Olsen and Kirschem, (2019) attempted to determine the conditions necessary to facilitate a decrease in emissions if the operator were to act altruistically and focus on emissions reductions over profitability. Additionally, the study modeled operation of the storage devices to maximize profitability with the stipulation that the energy storage device only operates when it would reduce emissions. The study examined the effects of a carbon tax on the outcomes of each of the strategies. It modeled the behavior of energy storage on a grid with $30 \%$ 
renewable energy supply and conducted a sensitivity analysis with RTE, amount of storage capacity, and energy pricing to determine the resulting impact on GHG emissions. It was determined that the conditions that facilitate a decrease in emissions required being selective when the battery was charged and discharged and operating only on days where the difference in marginal emissions was great enough to overcome the increased demand from energy losses.

Electrical vehicles (EVs) operate in a similar way to grid-tied energy storage devices and can be studied similarly to the way energy storage is. EVs store energy in a battery which is then used to propel the vehicle when discharged. The behavior patterns of EVs are different from that of grid-tied energy storage due to the different purposes for its operation. When studying the impact of batteries used for EVs it isn't a question of lowering emissions on the electrical grid since the vehicle is increasing the demand for energy when charging and not alleviating demand when it is discharging. Instead, studies looking at the GHG impact of EVs focus on comparative analyses between charging behaviors and emissions from gas-powered vehicles. One study looked at the GHG emissions associated with plug-in hybrid vehicle operation. Using driving patterns from the National Household Transportation survey to determine when there would be an additional demand for energy from the charging of these vehicles (Peterson, Whitacre, \& Apt, 2011). The resulting increase in emissions was determined using different scenarios, assuming the cheapest energy sources were dispatched first, with various carbon pricing scenarios. EVs can play a role in shifting demand through vehicle-to-grid energy transfers. With this potential management solution EVs, when plugged into the grid, can 
be used to meet demand during times with the most carbon intense energy mix and recharge using energy with a lower carbon intensity energy mix. The replacement of “dirtier" energy generation sources also offers a solution to environmental injustice issues caused by peaker plants. These less efficient plants are disproportionately located in lowincome and minority neighborhoods with half of California's natural gas power plants located in communities that rank among the $25 \%$ most disadvantaged (PSE, 2017).

\section{Charging and Discharging Strategies}

To gain the greatest benefit from a battery energy storage system, the timing of when to charge the battery and when to discharge it is critically important. Some key concepts that influence this decision are energy arbitrage, peak shaving, and overgeneration/curtailment of renewable sources. Energy arbitrage is the practice of purchasing and storing energy during off-peak/low price times and selling energy during peak, high price, hours. Peak shaving involves discharging the battery during times of peak demand to lower the stress on the electrical grid and potentially eliminate the need for older and less efficient sources (Cardwell \& Krauss, 2017). Energy storage can be operated with the intent of minimizing the risk of overgeneration and subsequent curtailment of renewable energy sources. Each of these approaches can be used in different combinations to rationalize numerous different battery use strategies.

Charging a battery during midday when net-demand is low and discharging at peak times to shift the demand for energy production away from peaker plants, follows the flattening the duck curve approach mentioned in the previous section. This strategy of battery operation would allow variable generation sources such as wind and solar to 
displace existing fossil fuel-based infrastructure. The leveling of net-demand also increases demand for energy generation during mid-day that can be met by new solar plus storage projects. This strategy is ideal to transition an electrical grid that intends to rely on either solar or wind power to meet its energy demand. It allows for the continued growth of renewable power production, preventing the deflation of the value of renewable power sources and increasing the amount of demand that they can meet. This approach would also maximize the reduction of emissions during the discharge of its energy storage devices.

As power-generating sources are deployed to meet demand, the cost to run the powerproducing source is used to determine the dispatch order. The grid operator prioritizes sources with the lowest costs, starting with renewables like wind and solar, which cost little to nothing to run, followed by other zero-carbon sources like nuclear and hydropower. Following these sources are base-loading natural gas turbines that are capable of operating 24 hours per day, then by less efficient natural gas sources that are more costly, less efficient and higher polluters (US EIA, 2012). In other states, coal would also play a prominent role in energy production. However, in California coal power plants make up less than one percent of energy generation, and those few remaining plants are to be retired in the near future. Power produced from coal can also come from out-of-state sources since California is a net importer of energy from neighboring states: the mix of this imported energy has no direct generation origin (IER, 2015). The MEF is the difference in GHG emissions per unit of change in energy generation: as demand increases, less efficient and more carbon-intensive sources are 
used. Operating a storage device for peak shaving and trough filling purposes means charging when net-demand is lowest and the MEF is likely to be lower, and discharging when net-demand is highest and MEF is likely to be higher.

Current battery operation patterns as recorded by CAISO - a nonprofit independent system operator that manages the flow of electricity across the high-voltage, long distance power lines for the grid serving $80 \%$ of California and a small part of Nevadalack a particular pattern. Instead, the energy storage operation is used to react to the needs of the electrical grid, providing important services beyond peak shaving and energy arbitrage. The majority of the existing energy storage capacity is dedicated to providing these grid services. Additional energy storage capacity would for the most part operate in a different manner, with the goal of growing renewables and operating to provide arbitrage services. In the case of a high solar penetration grid condition, the value of solar plus storage operating to provide energy arbitrage would beat standalone solar economically (Gerza, 2019).

\section{Battery Types and Impacts}

Some of the commonly used forms of storing energy currently are pumped hydro, compressed air, and batteries. In California, batteries appear to be the best option available for growing the state's energy storage capacity. Alternatives such as pumped hydro storage is limited by water supply and the need to maintain the flow of rivers, or compressed air energy storage, which often utilizes natural gas making it non-conducive with California's zero-carbon goal. Batteries, on the other hand, are limited by production capabilities, and while there are considerable environmental impacts associated with the 
production of batteries their operation is far more conducive with California's goals than the alternatives. Li-ion batteries are the most commonly used battery type for grid purposes due to its high RTE, lower emissions per unit of storage produced, and ability to turn on and off in a short period to react to grid needs (Liang et.al., 2017). The downfall of most battery storage devices is the resources utilized to produce the product and the environmental impact it has from cradle to grave or. This can be overcome if an adequate recycling program were to be developed. This would decrease the impacts from resource extraction for production and the disposal of the storage device at end of life.

The Li-ion battery is commonly used in many household products that run on battery power: your laptop, cellphone, and EV if you have one. Li-ion batteries are also one of the most prominent energy storage technologies used for electrical grid services. New "cleaner" and potentially more efficient rechargeable batteries such as vanadium redox flow, sodium-ion, and zinc manganese oxide provide a promise of improving on the existing technologies but are either too expensive, limited in resource availability, or too early in their development. If innovation is powered by a demand for battery technologies to drive the transition to cleaner energy sources, future battery innovations are expected to focus on improving RTE, durability, and reliability (Dunn et.al., 2011).

Li-ion batteries are produced with various internal chemistries, the impacts of producing these devices varies from type to type. A study examined the impacts determined across 79 LCA studies of Lithium Iron Phosphate (LFP), Lithium Iron Phosphate-Lithium Titanate (LFP-LTO), Lithium Cobalt Oxide (LCO), Lithium Manganese Oxide (LMO), Nickel Manganese Cobalt (NCM), and Nickel Cobalt 
Aluminum (NCA). In creating a Life Cycle Analysis of battery technology, the inputs that are required to create the end product are examined along with the impacts associated with each resource and with the creation of the final product (Peters, Baumann, Zimmerman, Braun, \& Weil, 2017. The impacts of each battery chemistry are shown in Table 1 below.

Table 1

Average Impact Per Wh by Li-ion Battery Chemistry Type

\begin{tabular}{|c|c|c|c|c|c|c|}
\hline Impact Category & LFP & $\begin{array}{l}\text { LFP- } \\
\text { LTO }\end{array}$ & LCO & LMO & NCM & NCA \\
\hline $\begin{array}{l}\text { Abiotic Depletion } \\
\text { (kg Sbe/Wh) }\end{array}$ & $1.00 \mathrm{E}-03$ & $\begin{array}{r}4.22 \mathrm{E}- \\
04\end{array}$ & NA & $\begin{array}{r}4.22 \mathrm{E}- \\
04\end{array}$ & $\begin{array}{r}8.86 \mathrm{E}- \\
04\end{array}$ & NA \\
\hline $\begin{array}{l}\text { Acidification Potential } \\
\left(\mathrm{kgSO}_{2} \mathrm{e} / \mathrm{Wh}\right)\end{array}$ & $1.29 \mathrm{E}-03$ & NA & $\begin{array}{r}1.50 \mathrm{E}- \\
03\end{array}$ & $\begin{array}{r}5.36 \mathrm{E}- \\
04\end{array}$ & $\begin{array}{r}2.03 \mathrm{E}- \\
03\end{array}$ & NA \\
\hline $\begin{array}{l}\text { Global Warming Potential } \\
\left(\mathrm{kgCO}_{2} \mathrm{e} / \mathrm{Wh}\right)\end{array}$ & $1.61 \mathrm{E}-01$ & $\begin{array}{r}1.85 \mathrm{E}- \\
01\end{array}$ & $\begin{array}{r}5.60 \mathrm{E}- \\
02\end{array}$ & $\begin{array}{r}5.50 \mathrm{E}- \\
02\end{array}$ & $\begin{array}{r}1.60 \mathrm{E}- \\
01\end{array}$ & $\begin{array}{r}1.16 \mathrm{E}- \\
01\end{array}$ \\
\hline $\begin{array}{l}\text { Eutrophication Potential } \\
(\mathrm{kgNe} / \mathrm{Wh})\end{array}$ & $2.72 \mathrm{E}-04$ & NA & NA & $\begin{array}{r}1.22 \mathrm{E}- \\
05\end{array}$ & $\begin{array}{r}1.52 \mathrm{E}- \\
04\end{array}$ & NA \\
\hline $\begin{array}{l}\text { Ozone Depletion Potential } \\
(\mathrm{kgCFCe} / \mathrm{Wh})\end{array}$ & $1.14 \mathrm{E}-06$ & NA & NA & $\begin{array}{r}4.68 \mathrm{E}- \\
09\end{array}$ & $\begin{array}{r}6.72 \mathrm{E}- \\
07\end{array}$ & NA \\
\hline $\begin{array}{l}\text { Human Toxicity } \\
\text { (kg1.4DCBe/Wh) }\end{array}$ & $2.60 \mathrm{E}-01$ & $\begin{array}{r}1.60 \mathrm{E}- \\
01\end{array}$ & $\begin{array}{r}2.40 \mathrm{E}- \\
01\end{array}$ & $\begin{array}{r}2.50 \mathrm{E}- \\
01\end{array}$ & $\begin{array}{r}4.82 \mathrm{E}- \\
01\end{array}$ & $\begin{array}{r}2.78 \mathrm{E}- \\
01\end{array}$ \\
\hline
\end{tabular}

Due to the scarcity of resources used to produce Li-ion batteries and the variety of purposes they are used for, there are reasons for concern over their future availability. Creative solutions can be implemented to maximize the usefulness of each unit of storage capacity. EV batteries once deemed not fit for powering a vehicle still have $60-80 \%$ of their original storage capacity available which can be used to provide grid services (Neubauer \& Pesaran, 2011). These batteries can be paired with solar projects to 
maximize the usefulness of the battery through its lifetime, conserving the resources that go into its production. However, the benefits from the operation of the EV batteries are less certain due to their dependence on grid conditions (Bobba, et. al., 2018). By repurposing EV batteries, the production needs for Li-ion batteries are decreased, reducing the environmental impacts from Li-ion battery production which accounts for the majority of the detrimental environmental impacts of the batteries' life cycle (Cusenza et.al., 2019). The repurposing of EV batteries stands to be more effective under projected future grid conditions where renewables account for a larger percentage of generation. Under these circumstances repurposed EV batteries would provide close to 12 years of service in grid-and self-consumption applications (Casals et.al., 2019). 


\section{Problem Statement}

For California's energy transition to carbon-free energy sources to continue, energy storage needs to be utilized to allow carbon-free VG sources to meet greater levels of demand and eventually reach the state's 2045 carbon-free goal. California's government has shown an interest in utilizing these technologies, pushing to expand energy storage capacity and its renewable energy portfolio by passing SB 700 which allocates funds for behind the meter energy storage projects that reduce GHG emissions ("Energy Storage Roadmap", 2014). Research has yet to be conducted to establish an adequate understanding of the impacts of energy storage device operation within California. Without this understanding, it is not possible to determine adequately whether now is the right time to push for increased energy storage capacity if the goal is lowering GHG emissions in the short term.

If adequate considerations are not taken before large amounts of energy storage is deployed onto the state's grid, short term increases in GHG emissions are possible. The demand for Li-ion batteries, currently the leading battery storage technology, will increase as a result of the push to increase energy storage capacity. Additionally, increasing the negative impacts of batteries throughout their life cycle by increasing demand can potentially jeopardize the future availability of scarce materials used to

produce this technology. In addition, the need for a policy using taxpayer dollars to fund energy storage deployment would be better understood if included an analysis of the financial impact compared to the price of a unit of Li-ion battery energy storage. 
Ideally, energy storage deployment would occur in conjunction with renewable energy projects at a point in time where their operation grows renewable energy and reduces GHG emissions. These storage devices could be co-located with the generation source, maximizing the value of energy produced there by storing energy generated and selling it to the grid when the price energy is higher. Or they could be near generation sources to allow the storage device to operate to meet the needs of the area, allowing a greater amount of daytime demand to be met by solar power sources. Energy storage utilized in California has the potential, under the right conditions, to grow the amount of wind and solar power by limiting curtailment, increasing financial viability, improving grid reliability, and appeasing the stresses of ramping to meet peak demand. However, if the operation of the storage device results in an increase in GHG emissions by growing the total demand for energy, the benefits of increasing California's storage capacity could be outweighed in the short term by the increased emissions and effects of increased demand for Li-ion batteries. 


\section{Study Objectives}

This study models the operation of $1 \mathrm{MWh}$ of energy storage to determine its impact on GHG emissions and the financial outcome from its operation. These energy storage devices are additional to the existing energy storage capacity on the CAISO grid. These additional storage devices are assumed to be spread throughout CAISO's territory to represent the average impact a storage device would have across CAISO during the 2019 calendar year. The devices are considered to be operating independent from an energy generation, storing and discharging energy that was pulled from the existing grid mix and returned to the grid without additional transmission or other potential sources of energy losses added.

The purpose of this study is to determine whether California's push to deploy new energy storage capacity to the electrical grid is conducive to its goal of decarbonizing its energy system, and to establish a better understanding of the impact different operation patterns would have. While renewable energy and its adjacent technologies are generally considered to be "green", much of the battery life cycle is fraught with negative impacts, from resource gathering through to disposal. If it is determined that increased battery use would not lower GHG emissions then, by deploying more of them, California would not achieve its goal of helping to decarbonize the electrical grid in the short term while also causing additional environmental harm through the increased demand for battery production.

The impact of batteries on GHG emissions was tested under different charging and discharging strategies likely to be implemented for an energy storage device. The first 
strategy is referred to as solar to meet peak net-demand: charging is timed to occur when solar production is highest, and discharging when net-demand is highest. The second is an energy arbitrage strategy that maximizes profitability, discharging when the price of energy is high and charging when it is low. The final strategy maximizes emissions reductions by charging when the MEF is lowest and discharging when it is highest. A sensitivity analysis was also conducted examining the effects of changes in round-trip efficiency to establish a factor representing the impact of an increase or decrease in efficiency of $1 \%$. Using the results from these conditions the following research questions were answered.

RQ1: Did additional energy storage devices deployed on California's electrical grid lower GHG emissions when operating in 2019?

RQ2: What is the minimum level of round-trip efficiency needed to operate energy storage devices that lower peak demand using stored solar energy to decrease emissions? RQ3: What is the minimum level of round-trip efficiency needed to operate energy storage devices that maximize profitability to decrease emissions?

RQ4: Which of the three operation scenarios is the most cost-effective way to reduce emissions, or minimize additional emissions, from energy storage operation? 


\section{Methodology}

\section{Study Site}

This study looks at the electrical grid covering CAISO's California territory as a whole, focusing on its energy generation and carbon intensity data. California was the focus of this study for its high level of solar penetration and government support for the increased deployment of renewable VG energy sources and storage. When an energy system relies heavily on VG sources to supply its energy demand, as California currently does, overgeneration is a common problem. California's high rate of solar power generation energy causes oversupply of energy to the grid, throwing its precise balance of energy generation and usage off, which results in the curtailment of renewable energy sources to address the imbalance, impacting the effectiveness and financial viability of renewable energy projects. In response, California has pushed for the deployment of energy storage systems to alleviate curtailment and help VG sources meet larger portions of the state's energy demand. The state also passed SB 700 in 2018 , which allocated $\$ 800$ million to the Self-Generation Incentive Program to fund projects implementing behindthe-meter energy storage devices. California has also created plans to efficiently implement higher renewable futures, identifying where development of transmission or energy storage is needed to accommodate the expected future conditions (CAISO "Energy Storage, Roadmap", 2014). The push for energy storage deployment does come with the risk of increasing statewide GHG emissions due to the power loss associated with storing energy, however this outcome would be dependent on the round-trip 
efficiency of the storage device and the disparity of MEFs during charging and discharging.

This study gathered one year of data from January 1st, 2019, to December 31st, 2019. The purpose of using a full year of data is to prevent seasonal variation from influencing results. The data also needed to be from the most recent year due to the rapidly growing supply of renewable energy on the state's grid. If this study were to look further back than a year it would be biased towards a lower renewable supply than would be encountered by a storage device deployed on January 1st, 2019.

A battery's useful lifetime can vary depending on its operating conditions and maintenance, and if deployed on 01/01/19 would most likely be operational well beyond the end of 2019. Data for energy demand and generation beyond 2019 was not available when this study was conducted, therefore this study did not look at the impact of batteries throughout their life but instead focused on their impacts on grid emissions in 2019.

\section{Study Design}

This study used a full year of energy production data, taken from the CAISO website, to model the operation of energy storage devices spread across the California electrical grid. The impact on GHG emissions and the profitability from the operation of $1 \mathrm{MWh}$ of energy storage capacity operating in 2019 was determined. The model was designed so that devices had charge and discharge lengths of four hours in a non-continuous manner, meaning the four hours can be spread out across the 24-hour period and not just in one four-hour block. The times during which the batteries are charging or discharging were determined under the three different use strategies described on page 25. However, the 
specific replacing and displaced energy generation sources could not be determined. Instead, MEFs provided by Watttime were used, taking the average factor of each of the three grid markets, (SP15, NP15, and ZP26) within CAISO territory for every point during which batteries were considered to be charging or discharging. Those three regions were selected as the comprise the entirety of CAISO's California territory and a small portion of Nevada. The standard scenario assumes an RTE of $90 \%$, with a charging and discharging time of four hours, and does not account for curtailment alleviation. Each condition is then re-run with curtailment alleviation included, using the time-of-day hours where CAISO reports a system-wide curtailment event greater than or equal to $26 \mathrm{MWh}$ and the 5-minute data point reports greater than $2.083 \mathrm{MWh}$, which is the amount of energy stored if $100 \mathrm{MWh}$ were deployed and charged over four hours. The parameters set for the charging data points that alleviated curtailment were arbitrary, but deliberately conservative.

The RTE was adjusted to $91 \%$ to determine the impact a change in efficiency had on the financial and emissions outcomes. Using the time of operation for each strategy, the average price across CAISO, and the carbon intensity factors generated by Watttime, sensitivity factors for the change in emissions and profitability were determined for each operation pattern. These factors represented the change that would result from a $1 \%$ increase or decrease in RTE. The results for each run condition and the sensitivity factor from the sensitivity analysis were then used to determine critical points for RTE where emissions begin to be reduced and the operation of the storage device would begin to make a profit. 


\section{Hours of Operation/ Use Strategies}

The first step in addressing this study's research goals is to determine the optimal time for batteries to be charged and discharged. Each of the three use strategies targeted a particular pattern that storage devices would be likely to operate in. The first strategy charges batteries when solar power production is highest and discharges to meet peak net-demand. A typical example of this operation pattern involves charging in the middle of the day and discharging during the evening peak energy times. The second strategy is the energy arbitrage strategy that sets charging times for storage devices when prices are lowest and discharging times when prices are highest to maximize the devices' profitability. This pattern typically charges at times where there is low net-demand for energy, usually during mid-day or middle of the night, and discharges at peak netdemand times, which are either the evening peak or the morning peak between 6 a.m. and 9 a.m. The third strategy uses the MEF to maximize emissions reduction by charging when the MEF is lowest and discharging when it is highest. This strategy has an irregular pattern as the MEF values can be influenced by multiple factors, which means optimal charging and discharging times can occur at almost any time of day.

\section{Marginal Emissions Analysis}

Once the hours during which the battery will charge and discharge throughout the year are determined, the carbon intensity of the replacing and displacing energy sources needs to be established. Unfortunately, there is no reasonable way to determine which particular energy source would increase or decrease its production in response to the operation of an additional unit of stored energy. Therefore, the carbon intensity of an 
additional unit of energy generation is what will be found and reported in pounds of $\mathrm{CO}_{2} \mathrm{e}$ per MW. This was calculated using Watttime's MEFs, which are generated every five minutes using real-time grid data and machine learning to establish MEFs for regions across the continent. For this study, the factors from CAISO regions NP 15, ZP 26, and SP 15 were used to establish an average factor for CAISO as a whole. The resulting factor represents the average impact of the devices if spread out across CAISO territory.

\section{Financial Impacts}

The price of energy is published by CAISO by grid location nodes since the price varies widely depending on local supply, transmission, demand, and many other factors. The average financial effect of battery operation was determined using the average of all nodes. The profitability of one MWh of additional energy storage was determined by multiplying the amount of energy stored or discharged at each data point and subtracting the total charging data points from the total discharging data points. For example, on a given day a storage device charged during times when the average price of energy is $\$ 31 / \mathrm{MWh}$ and discharged during times of the day when the average price is $\$ 43 / \mathrm{MWh}$. With a 90\% RTE that would make a cost from charging of \$31 and an income from discharging of $\$ 38.70$ creating a total income from operation of the storage device of $\$ 7.70$ for the day. Calculating the year's operation of the storage device was then compared to a sample price of a Li-ion battery from Fu. Remo and Margolis, 2018, of $\$ 380 / \mathrm{kWh}$ or $\$ 380,000 / \mathrm{MWh}$ with a lifetime of 10 years, making the income needed per year to cover costs of the storage devices modeled in this study $\$ 38,000$. 


\section{Sensitivity Analysis}

A sensitivity analysis was conducted to establish the critical point where energy storage operation yields a decrease in emissions. The change in emissions that a $1 \%$ difference in RTE would have on the operation of 1MWh of storage was determined by running each operation pattern under a different RTE. Each scenario was run at $90 \%$ RTE then rerun with a $91 \%$ RTE: the difference between the $91 \%$ and $90 \%$ results is the total change in emissions that a percentage change in efficiency would impart. Using this value, it can be determined where the critical point is for emissions reduction by taking the change in emissions at $90 \%$ and dividing it by the change in emissions imparted by a $1 \%$ change in efficiency. The resulting value represents the percentage increase or decrease in efficiency required to reach the point where emissions would begin to be reduced. The same can be done to find the breakeven RTE point for the financial impact at which battery operation begins to make a profit. 


\section{Results}

While modeling the operation of additional energy storage devices there were challenges when it came to designating the times storing energy alleviated the curtailment of renewable energy sources. Since specific locations were not assigned to the storage devices included in this study, significant assumptions were required to assign curtailment alleviation to data points designated for charging under any of the strategies. Charging during these data points resulted in no new demand for energy, meaning there was no increase in emissions at that data point. The result of scenarios that did account for curtailment alleviation were determined using a minimum threshold set for reported system curtailment in order to provide a conservative estimate of the impact that additional energy storage capacity would have on curtailment reduction. There was also an issue with missing marginal emissions and pricing data, which was overcome by extrapolating using the five-minute data points around the missing data. There was also misreported data caused by reported maintenance on October 1 st and $2 \mathrm{nd}$, the result of which meant that the operation times could not be created since the factors used to set the times were either missing or misreported.

This study does not reflect expected outcomes for specific projects that implement energy storage devices since they would experience location-specific MEFs that differ from the average value used in this model. Instead, the goal was to establish an average impact to better assess the value of energy storage deployment throughout CAISO territory, and the factors that indicate ideal operation patterns both for reducing emissions 
and reducing financial impacts. The results of the three run conditions both with and without curtailment alleviation are listed in Table 2 below.

Table 2

Impact by Operation Profile With and Without Curtailment 90\%RTE

\begin{tabular}{|c|c|c|}
\hline & $\begin{array}{c}90 \% \text { RTE } \\
\left(\Delta \text { Metric Tons } \mathrm{CO}_{2} \mathrm{e}\right)\end{array}$ & $\begin{array}{c}\text { Sensitivity Factor } \\
\left.\text { ( } \Delta \text { Metric Tons } \mathrm{CO}_{2} \mathrm{e} / \Delta \% \mathrm{RTE}\right)\end{array}$ \\
\hline $\begin{array}{c}\text { Energy Arbitrage } \\
\text { Without Curtailment } \\
\text { Alleviation }\end{array}$ & $8,190.43$ & 757.06 \\
\hline $\begin{array}{c}\text { Solar to Meet Peak } \\
\text { Without Curtailment } \\
\text { Alleviation }\end{array}$ & $7,131.26$ & 749.32 \\
\hline $\begin{array}{c}\text { Optimized } \\
\text { Without Curtailment } \\
\text { Alleviation } \\
\end{array}$ & $-7,562.22$ & 826.04 \\
\hline $\begin{array}{c}\text { Energy Arbitrage } \\
\text { With Curtailment } \\
\text { Alleviation }\end{array}$ & $-2,204.35$ & 757.06 \\
\hline $\begin{array}{c}\text { Solar to Meet Peak } \\
\text { With Curtailment } \\
\text { Alleviation }\end{array}$ & $-2,074.47$ & 749.32 \\
\hline $\begin{array}{c}\text { Optimized Emissions } \\
\text { With Curtailment } \\
\text { Alleviation }\end{array}$ & $-9,611.64$ & 826.03 \\
\hline
\end{tabular}

The analysis shows the change in emissions of operating $1 \mathrm{MWh}$ of energy storage capacity throughout 2019, charging and discharging fully each day. Each condition has a sensitivity factor which represents the change in emissions that results from changing the RTE by $1 \%$. This value was used to identify critical points for the RTE where emission reductions can be detected and where battery use would begin to break even financially. The critical point was then compared to Li-ion batteries with an upper limit of RTE set at 
95\% to address whether a storage device could reduce emissions. The highest of the two critical points between the financial impact and change in emissions critical points were used to answer the question of whether a device could reduce emissions while producing a profit in 2019.

\section{Research Question 1}

Did additional energy storage devices deployed on California's electrical grid lower GHG emissions when operating in 2019?

To determine whether energy storage could reduce emissions during the 2019 calendar year a 90\% RTE four-hour discharge condition was used, assuming no curtailment alleviation while using the optimized emissions strategy. Using the results of the run with 90\% RTE and the generated sensitivity factor would put the critical point under the $95 \%$ cap. Running the model under these conditions resulted in a 7,562 lbs $\mathrm{CO}_{2} \mathrm{e}$ reduction in emissions. This means that operating $1 \mathrm{MWh}$ of energy storage in

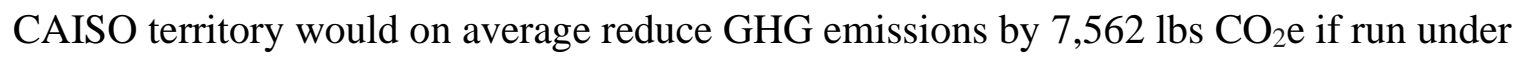
the pattern that minimizes GHG emissions. When curtailment alleviation is considered the change in emissions is further reduced by $2,049 \mathrm{lbs} \mathrm{CO}_{2} \mathrm{e}$ for a total reduction of 9,611 lbs $\mathrm{CO}_{2} \mathrm{e}$.

Using the sensitivity analysis, altering the RTE by $1 \%$ resulted in a change in emissions of $826 \mathrm{lbs}$ of $\mathrm{CO}_{2}$ e per percentage change in RTE: Figure 2 shows the change in emissions for RTEs between $80 \%$ and $95 \%$. By dividing the change in emissions by this factor the change in RTE to reach the critical point was $80.85 \%$ if curtailment alleviation is not considered. With curtailment alleviation, the critical point for emissions 
was $78.36 \%$ RTE. These critical RTEs show that if emissions reductions are prioritized, it is possible to achieve reduced emissions under 2019 conditions even when curtailment alleviation is not accounted for. Such condition would require the MEF throughout each day to be predicted accurately. However, this is difficult to do because the MEF can be altered by any one of numerous factors that can be incorrectly predicted making this operation pattern difficult to accurately replicate.

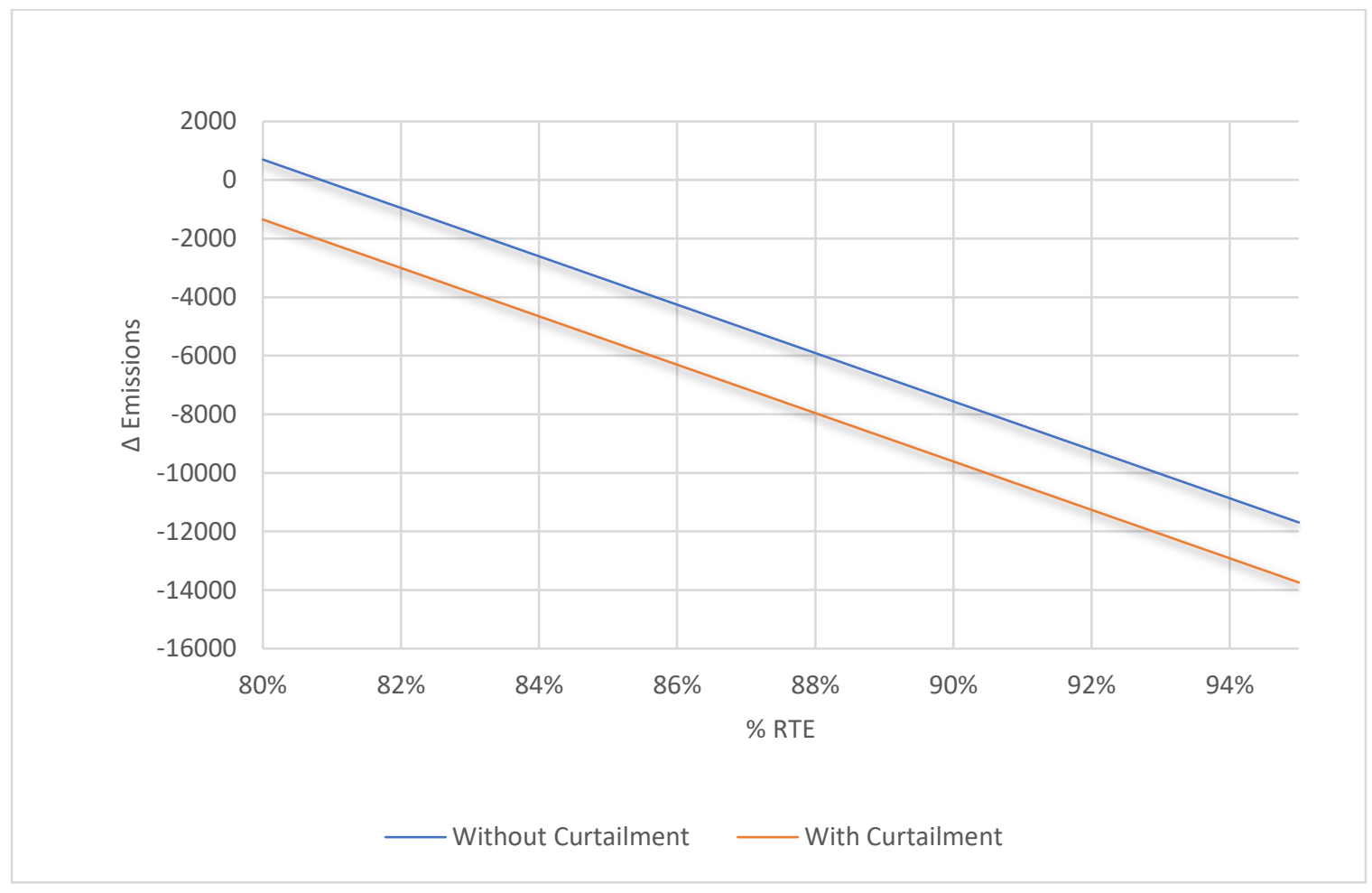

Figure 2. Change in emissions by round trip efficiency for the optimized emissions operation pattern both with curtailment alleviation and without. 


\section{Research Question 2:}

What is the minimum level of round-trip efficiency needed to operate energy storage devices that lower peak demand using stored solar energy to decrease emissions?

The solar to meet peak net-demand strategy involves operating energy storage devices to emphasize the growth of solar by maximizing the times where solar production is highest for charging and using that energy to lower peak demand. The result of this operation pattern under the four-hour discharge and 90\% RTE conditions, without

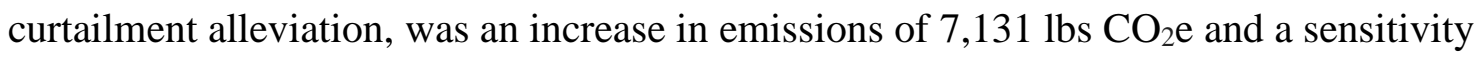
factor of $749 \mathrm{lbs} \mathrm{CO}_{2} \mathrm{e}$. The sensitivity factor shows that to reach the break-even critical point the RTE needs to be above 99.52\% RTE if curtailment alleviation isn't included. This efficiency level is higher than current and projected future RTEs, meaning this strategy without curtailment alleviation would not have reduced emissions in 2019. When curtailment alleviation is taken into account, the impact on emissions drops by 9,205 lbs $\mathrm{CO}_{2} \mathrm{e}$ to a total decrease in emissions of 2,074lbs CO2e. The sensitivity factor is the same as the zero-curtailment condition of $749 \mathrm{lbs} \mathrm{CO}_{2} \mathrm{e}$, which gives a critical RTE of $87.09 \%$. Therefore, using solar to meet peak net- demand while using the conditions for curtailment alleviation laid out in this study has the potential to reduce emissions with currently available energy storage technology. Full results for the change in GHG emissions between $80 \%$ and 95\% RTE can be found in Figure 3 below. 


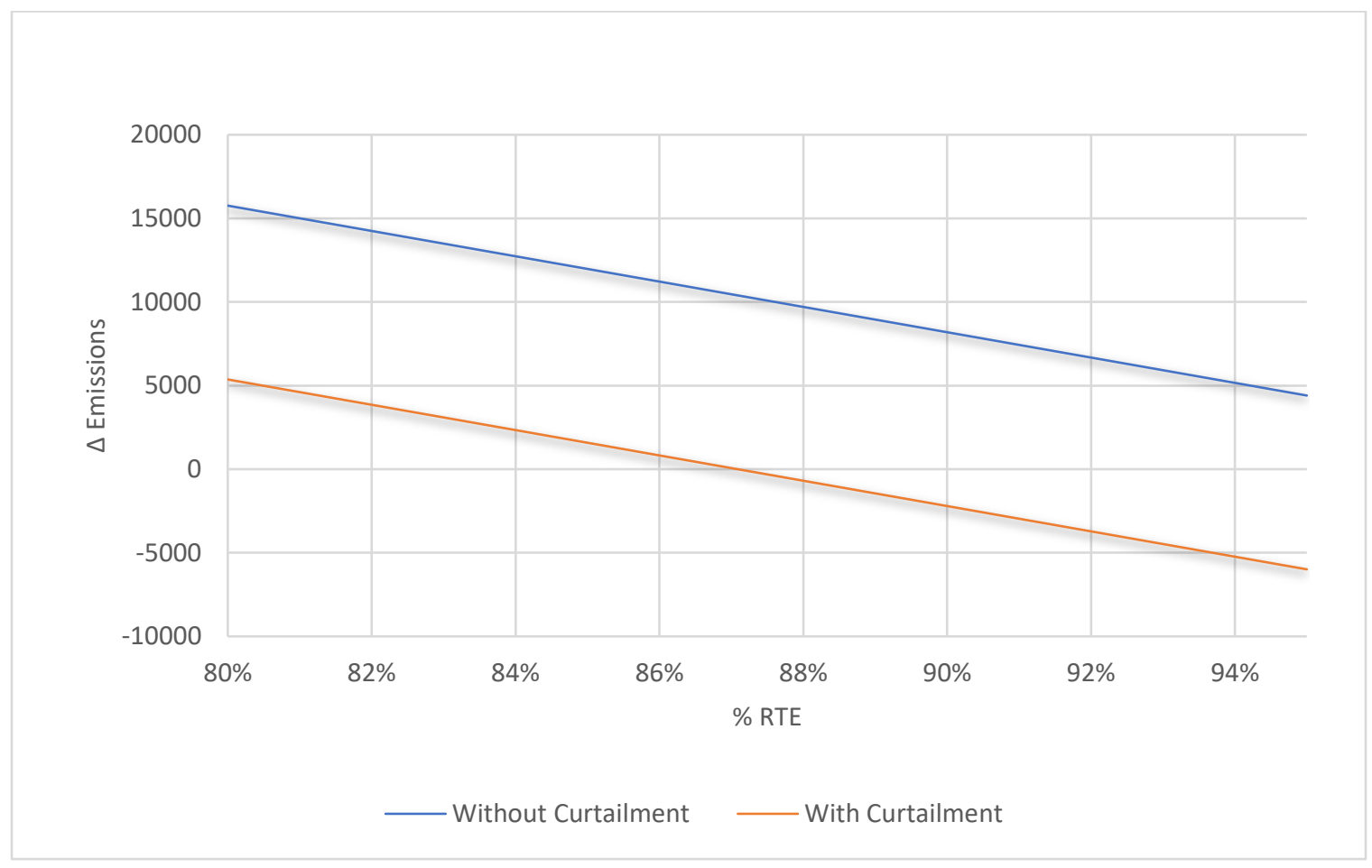

Figure 3. Change in emissions by round trip efficiency for the solar to meet peak netdemand operation pattern both with curtailment alleviation and without.

\section{Research Question 3:}

What is the minimum level of round-trip efficiency needed to operate energy storage devices that maximize profitability to decrease emissions?

When energy storage devices are operated to maximize financial benefits, the incentive to deploy the devices increases. The impact on emissions of running these devices for a one-year period under 90\% RTE, 4-hour discharge, and without curtailment alleviation was an increase of $8,190 \mathrm{lbs} \mathrm{CO}_{2} \mathrm{e}$. The sensitivity factor for this condition was $757 \mathrm{lbs} \mathrm{CO}_{2} \mathrm{e}$, which gives a critical RTE of $100.82 \%$, meaning without curtailment alleviation it would not be possible to reduce emissions under this operation strategy. When including curtailment alleviation in this operation pattern, the emissions were 
reduced by $10,394 \mathrm{lbs} \mathrm{CO}_{2} \mathrm{e}$. This results in a total decrease of 2,074 $\mathrm{lbs}_{\mathrm{CO}_{2}} \mathrm{e}$ from this

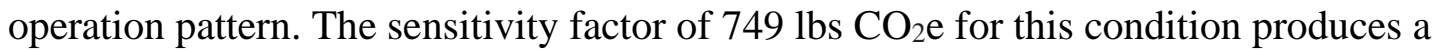
critical RTE of $87.23 \%$. With curtailment alleviation, this strategy would reduce emissions using an RTE that can be found in current technologies. Full results for the change in GHG emissions between 80\% and 95\% RTE can be found in Figure 4 below.

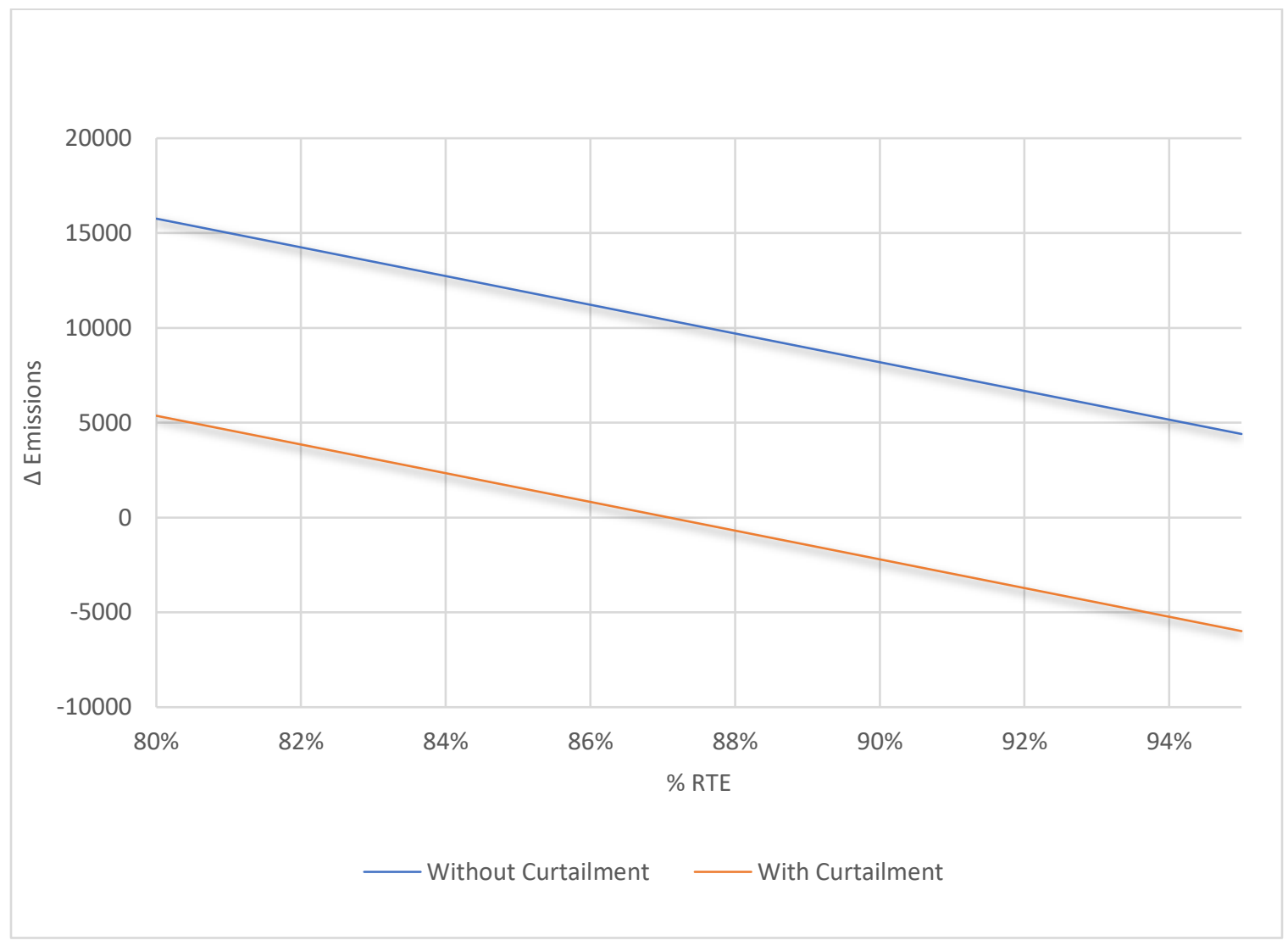

Figure 4. Change in emissions by round trip efficiency for the energy arbitrage operation pattern both with curtailment alleviation and without. 


\section{Research Question 4:}

Which of the three operation scenarios is the most cost-effective way to reduce emissions, or minimize additional emissions, from energy storage operation?

The financial impact of energy storage device operation is an important factor in determining how the device would be run if deployed or whether the device is worth deploying. As California intends to provide financial incentives to help grow the energy storage capacity available in the state, an understanding of the amount of financial assistance required to make the device financially viable is needed. For energy storage to be financially viable without state assistance, it would have to overcome the $\$ 380,000$ cost of $1 \mathrm{MWh}$ of energy storage capacity. The possible outcomes for Li-ion batteries length of life and deterioration over time can vary greatly, and future grid conditions can alter the impact on emissions and potential profitability of operation. Therefore, for this research question profitability over the lifetime of the storage devices was not examined. Instead, the amount of the cost that is recuperated during a single year, 2019, was examined along with the change in emissions.

The financial impact from operation during 2019, in Table 3 below shows that the energy arbitrage strategy, as expected, created the greatest profit at $\$ 20,239.07$. The solar to meet peak net-demand approach made $\$ 9,399.50$ profit and the optimized emissions strategy made $\$ 959.39$ profit. This left most of the upfront costs of deploying $1 \mathrm{MWh}$ of energy storage unmet. Specifically, if spread out over the course of a ten-year lifetime, the energy arbitrage strategy would have $\$ 17,760.93$ left of upfront costs, $\$ 28,600.50$ for 
the solar to meet peak net-demand approach, and $\$ 37,040.61$ of upfront costs left for the optimized emissions strategy.

With curtailment alleviation each of the three operation patterns resulted in a reduction of emissions at an RTE under 95\%. When the total cost is spread out across a ten-year lifetime, the cost per unit of emissions reduction can be determined using the values presented in Table 3 below for emissions reduction and battery costs in 2019. The cost per unit of emissions reductions for each of the three operation profiles was used to determine which was the most cost-effective way of reducing emissions. The breakdown of this analysis is presented in Table 3 as well below showing the change in emissions and profitability as well as the cost per $\mathrm{lb} \mathrm{CO} 2 \mathrm{e}$ reduction.

Table 3

Impacts of Operating 1MWh of Energy Storage at 90\% RTE Energy and the Cost per Unit of Emission Reduction for Each Strategy.

\begin{tabular}{|c|c|c|c|c|}
\hline \multicolumn{2}{|c}{$\begin{array}{c}\Delta \text { Emissions } \\
\mathbf{C O}_{2} \mathbf{e}\end{array}$} & Profit & Net-Cost & $\begin{array}{c}\text { Cost per lb CO } \\
\text { reduction }\end{array}$ \\
\hline $\begin{array}{c}\text { Energy } \\
\text { Arbitrage }\end{array}$ & $-2,204$ & $\$ 20,239.07$ & $\$ 17,760.93$ & $\$ 8.06$ \\
\hline $\begin{array}{c}\text { Solar to meet } \\
\text { peak }\end{array}$ & $-2,074$ & $\$ 9,399.50$ & $\$ 28,600.50$ & $\$ 13.79$ \\
\hline $\begin{array}{c}\text { Optimized } \\
\text { Emissions }\end{array}$ & $-9,611$ & $\$ 959.39$ & $\$ 37,040.61$ & $\$ 3.85$ \\
\hline
\end{tabular}

The optimized emissions pattern, despite being the least cost-efficient operation, was the cheapest way of reducing emissions at $\$ 3.85$ per $1 \mathrm{~b}$ reduction of $\mathrm{CO}_{2}$ e due to the larger total emissions reduction. This was followed by the energy arbitrage pattern of $\$ 8.06$ per $\mathrm{lb}$ of $\mathrm{CO}_{2} \mathrm{e}$ emissions, then solar to meet peak net-demand at $\$ 13.79$ per lb of $\mathrm{CO}_{2} \mathrm{e}$ emissions. 


\section{Discussion}

With California pushing to increase its energy storage capacity, an understanding of the potential impacts this capacity would have on GHG emissions is vital. Ideally, the operation of an energy storage device would both be profitable and reduce emissions. From the model developed for this study, it is clear that on average an energy storage device deployed onto the grid within CAISO territory would reduce emissions if operated optimally. Assuming a relatively accurate 24 hour ahead forecast of MEFs the operation of an energy storage device independent from a generation source would be able to reduce emissions with an RTE of over $78.41 \%$ when curtailment alleviation is considered and $80.95 \%$ when it is not. These results show that energy storage devices can technically operate in CAISO territory in a manner that reduces emissions. However perfect knowledge of the MEF is not possible and predicting MEFs ahead of time is difficult due to the many factors that can have an influence on the MEF at any given time. Due to this unpredictability, the optimized emissions strategy is not one that can be replicated accurately in real-time. The purpose of examining this operation pattern was to determine whether it was technically possible to reduce emissions and determine the best possible outcome concerning emissions.

The other two strategies are easier to assess because the factors guiding charging and discharging times are more predictable than the MEF. The energy arbitrage and solar to meet peak net-demand strategies both yielded emissions reductions when modeled with curtailment alleviation at RTEs available on the energy storage market at the start of 2019. Each of these strategies had a large reduction of emissions resulting from the 
charging of storage devices during data points that experienced a curtailment event. The energy arbitrage strategy saw carbon emissions reduction of 2,204 lbs and the solar to meet peak net-demand strategy saw a 2,074 lbs reduction when operating with a 90\% RTE. These reductions highlight the importance curtailment alleviation would play for any new project looking to deploy energy storage, grow renewables, and/or reduce GHG emissions. They also demonstrate that the price of energy is a better factor for predicting curtailment events than the amount of solar energy being produced. This is likely due to the drop in the value of energy that occurs when there is a high risk of overgeneration to the grid or low net-demand for energy.

Making the operation of an energy storage device profitable is difficult without some form of governmental assistance at this time. The price point used here of $\$ 380,000 / \mathrm{MWh}$ would not be overcome with current pricing patterns assuming a device can operate at the deployed capacity for ten years. When operating in the most profitable manner possible the $1 \mathrm{MWh}$ of energy storage capacity still falls short of breaking even by $\$ 17,761$ when operating for ten years under the same conditions as 2019 . Under other operation strategies, the gap between the cost and money brought in through operation is even greater: $\$ 28,600.50$ for the solar to meet peak net demand strategy and $\$ 37,040.61$ for the optimized emissions strategy.

These results should be looked at using a broad lens when considering policy or other pushes to increase the energy storage capacity across CAISO territory. Specifically, the average impact of energy storage in CAISO territory demonstrated here should be used in guiding policy aimed at pursuing increased energy storage capacity throughout 
the state. The findings do not apply to individual projects due to the variability of local energy demand, energy sources, and prices, rather the results of this study provide a view of the average impact energy storage devices would have if deployed within CAISO territory during the year 2019. Further, these results represent the average impact of these devices since the models used data that represented the average or total value for all of CAISO territory. For these reasons, the results should not be used to estimate the impact a specific project using energy storage would have. Instead, an analysis should be conducted using the methods from this study and local factors to determine the effectiveness of an energy storage device to reduce emissions and be financially viable in a specific area.

The minimum RTE needed to make the deployment of an energy storage device beneficial is difficult to define. With the impacts on emissions and financial outcomes both being important factors in the decision. If the goal is purely to reduce emissions then the minimum RTE can be set at the point where emissions begin to be reduced. However, deployment of devices at this critical point would require greater financial aid to provide enough incentive for private entities to invest in them. At this time, without financial support, the deployment of an energy storage device would not, by itself, be able to overcome the cost of the device through the income generated by its operation.

\section{Conclusions}

From the results of this study, I suggest a policy aimed at providing state funding to build projects that utilize energy storage if they meet the following four requirements. First, storage devices would need an RTE of over $87 \%$, the value at which the energy 
arbitrage and solar to meet peak net-demand operation patterns begin to reduce emissions. Second, the project must be paired with, or in some way operate alongside, a renewable energy source. Third, the aforementioned renewable energy source should be in an area where curtailment is already a prevalent issue, allowing the storage device to maximize its curtailment alleviation potential. Finally, the device should be operated in a manner similar to the ones modeled in this study, using energy arbitrage, solar to meet peak net demand, or the optimized emissions scenarios if the MEF can be predicted accurately.

As the price per unit of energy storage capacity drops, the need for such a policy will decrease and could be phased out, similar to the path that solar power has taken in California. With considerable resources going toward research and development that focuses on improving efficiency and developing "cleaner" and more ethical alternatives to Li-ion batteries, important technological improvements can be expected in the near future. Due to these anticipated improvements, a reduction in prices is expected to occur, with projections ranging from $\$ 338$ per $\mathrm{kWh}$ to $\$ 124$ per $\mathrm{kWh}$ by 2030 , and between $\$ 258$ per kWh to $\$ 76$ per kWh by the year 2050 (Cole \& Frazier, 2019).

SB 700 and its stipulation that energy storage devices should reduce emissions is a good policy if there is a set of criteria in place that establishes what emissions-reducing energy storage entails. The previously described parameters would be an example of what this might look like, with developments expected to yield improved battery technology that is more likely to reduce emissions and be financially viable. Further, as 
curtailment becomes more prominent, the benefits of increased storage capacity will also grow as long as renewable energy growth continues.

Over the next few years, the growth in the energy storage capacity on CAISO's electrical grid will be key to continuing the decarbonizing process. However, the negative environmental impacts from the production of Li-ion batteries emphasizes the need to ensure the deployment of energy storage provides immediate environmental benefit. For this reason, the growth of energy storage in CAISO territory, and in any other electrical grid system with high renewable penetration, should occur alongside the deployment of renewable energy sources. Starting around the time where the electrical grid reaches a condition in which overgeneration caused by VG sources is as common as it was in California in 2019. Under those grid conditions, the financial impact is minimal under $2019 \mathrm{Li}$-ion battery prices, and emissions reductions are achievable under the strategies described in this study. Continuing to conduct studies like this throughout the energy transition will help to ensure its completion occurs quickly and efficiently, minimizing resource consumption by maximizing the positive impacts of the energy storage resources deployed. 


\section{References}

Advancing-Maximizing Value of Energy Storage Technology California Roadmap. (2014, December 31). Retrieved from http://www.caiso.com/Documents/AdvancingMaximizingValueofEnergyStorageTechnology_CaliforniaRoadmap.pdf

Arbabzadeh, M., Johnson, J. X., Keoleian, G. A., Rasmussen, P. G., \& Thompson, L. T. (2016). Twelve principles for green energy storage in grid applications. Environmental Science \& Technology, 50(2), 1046-1055.

Bobba, S., Mathieux, F., Ardente, F., Blengini, G. A., Cusenza, M. A., Podias, A., \& Pfrang, A. (2018). Life cycle assessment of repurposed electric vehicle batteries: an adapted method based on modelling energy flows. Journal of Energy Storage, 19, 213-225.

Branker, K., Pathak, M. J. M., \& Pearce, J. M. (2011). A review of solar photovoltaic levelized cost of electricity. Renewable and Sustainable Energy Reviews, 15(9), 4470-4482.

Casals, L. C., García, B. A., \& Canal, C. (2019). Second life batteries lifespan: rest of useful life and environmental analysis. Journal of Environmental Management, 232, 354-363.

Cardwell, D., \& Krauss, C. (2017, May 26). Coal Country’s Power Plants are Turning Away from Coal. Retrieved from https://www.nytimes.com/2017/05/26/business/energy-environment/coal-powerrenewable-energy.html.

Cobalt Statistics and Information. (2020, September). Usgs.Gov. https://www.usgs.gov/centers/nmic/cobalt-statistics-and-information

Cole, W. J., \& Frazier, A. (2019). Cost Projections for Utility-Scale Battery Storage. Retrieved from https://www.nrel.gov/docs/fy19osti/73222.pdf

Cusenza, M. A., Bobba, S., Ardente, F., Cellura, M., \& Di Persio, F. (2019). Energy and environmental assessment of a traction lithium-ion battery pack for plug-in hybrid electric vehicles. Journal of Cleaner Production, 215, 634-649.

Denholm, P., O'Connell, M., Brinkman, G., \& Jorgenson, J. (2015) Overgeneration From Solar Energy in California. a Field Guide to the Duck Chart. Retrieved from https://www.nrel.gov/docs/fy16osti/65023.pdf 
Denholm, P., \& Margolis, R. (2016). Energy Storage Requirements for Achieving 50\% Solar Photovoltaic Energy Penetration in California. Retrieved from https://www.nrel.gov/docs/fy16osti/66595.pdf

Denholm, P. L., \& Margolis, R. M. (2018). The Potential for Energy Storage to Provide Peaking Capacity in California Under Increased Penetration of Solar Photovoltaics. Retrieved from https://www.nrel.gov/docs/fy18osti/70905.pdf

Denholm, P. L., Margolis, R. M., \& Eichman, J. D. (2017). Evaluating the Technical and Economic Performance of PV Plus Storage Power Plants. Retrieved from https://www.nrel.gov/docs/fy17osti/68737.pdf

Dunn, B., Kamath, H., \& Tarascon, J. M. (2011). Electrical energy storage for the grid: a battery of choices. Science, 334(6058), 928-935.

European Commission, Communication from the Commission to the European Parliament, the Council, the European Economic and Social Committee, and the Committee of the Regions on the 2017 List of Critical Raw Materials for the EU. (COM/2017/490, European Commission, Brussels, 2017).

Fares, R. L., \& Webber, M. E. (2017). The impacts of storing solar energy in the home to reduce reliance on the utility. Nature Energy, 2(2), 1-10.

Fu, R., Remo, T. W., \& Margolis, R. M. (2018). 2018 US Utility-Scale PhotovoltaicsPlus-Energy Storage System Costs Benchmark. Retrieved from https://www.nrel.gov/docs/fy19osti/71714.pdf

Gallo, A. B., Simões-Moreira, J. R., Costa, H. K. M., Santos, M. M., \& Dos Santos, E. M. (2016). Energy storage in the energy transition context: a technology review. Renewable and Sustainable Energy Reviews, 65, 800-822.

Gerza, Adam. (2019, March 28). Case study: When Solar+Storage Operating in Time-ofUse Arbitrage Mode Beats the Economics of Standalone Solar. Retrieved from https://www.solarpowerworldonline.com/2019/03/case-study-when-solarstorageoperating-in-time-of-use-arbitrage-mode-beats-the-economics-of-standalone-solar/

Golden, R., \& Paulos, B. (2015). Curtailment of renewable energy in California and beyond. The Electricity Journal, 28(6), 36-50.

Griffiths, B. (2019). Reducing emissions from consumer energy storage using retail rate design. Energy Policy, 129, 481-490. 
Gupta, Mitalee. (2019, February 12). DC-Coupled Solar-Plus-Storage Systems Are Gaining Ground. Retrieved from https://www.greentechmedia.com/articles/read/dc-coupled-solar-plus-storagegaining-ground

Hill, C. A., Such, M. C., Chen, D., Gonzalez, J., \& Grady, W. M. (2012). Battery energy storage for enabling integration of distributed solar power generation. IEEE Transactions on Smart Grid, 3(2), 850-857.

Intergovernmental Panel on Climate Change (IPCC). (2018). Global warming of $1.5^{\circ} \mathrm{C}$. Retrieved from https://report.ipcc.ch/sr15/pdf/sr15_spm_final.pdf

Lazar, J. (2016). "Teaching the" Duck to Fly.” Regulatory Assistance Project. Retrieved from https://www.raponline.org/knowledge-center/teaching-the-duck-to-fly-secondedition/

Liang, Y., Su, J., Xi, B., Yu, Y., Ji, D., Sun, Y., \& Zhu, J. (2017). Life cycle assessment of lithium-ion batteries for greenhouse gas emissions. Resources, Conservation and Recycling, 117, 285-293.

Luoma, J., Mathiesen, P., \& Kleissl, J. (2014). Forecast value considering energy pricing in California. Applied Energy, 125, 230-237.

Ndiaga, T., \& Rumney, E. (2019, March 14). Burkina Faso Wins Manganese Case Against Mining Group. Retrieved from https://www.businesslive.co.za/bd/world/africa/2019-03-14-burkina-faso-winsmanganese-case-against-mining-group/

Nyberg, M., (2019) Total System Electric Generation. California Energy Commission. Received from https://www.energy.ca.gov/data-reports/energy-almanac/californiaelectricity-data/2019-total-system-electric-generation

Olsen, D. J., \& Kirschen, D. S. (2019). Profitable emissions-reducing energy storage. IEEE Transactions on Power Systems. 35, 1509-1519.

Peters, Jens F., Baumann, M., Zimmerman, B., Braun, J., Weil, M. (2017) The environmental impact of li-Ion batteries and the role of key parameters - A review. Renewable and Sustainable Energy Reviews, 67, 491-506.

Peterson, S. B., Whitacre, J. F., \& Apt, J. (2011). Net air emissions from electric vehicles: the effect of carbon price and charging strategies. Environmental Science \& Technology 2011 45(5), 1792-1797. 
Mulvaney, D. (2019). Solar power: Innovation, Sustainability, and Environmental Justice. Berkley, CA: University of California Press.

Neubauer, J., \& Pesaran, A. (2011). "The ability battery second use strategies to impact plug-in electric vehicle prices and serve utility energy storage applications. Journal of Power Sources, 196(23), 10351-10358.

Roberts, D. Solar Power's Greatest Challenge Was Discovered 10 Years Ago. It Looks like a Duck. Retrieved from https://www.vox.com/energy-andenvironment/2018/3/20/17128478/solar-duck-curve-nrel-researcher

Shaker, H., Zareipour, H., \& Wood, D. (2016). Impacts of large-scale wind and solar power integration on California' s net electrical load. Renewable and Sustainable Energy Reviews, 58, 761-774.

Sherwood, D. (2018). A Water Fight in Chile's Atacama Raises Questions over Lithium Mining. Retrieved from https://www.reuters.com/article/us-chile-lithium-insightidUSKCN1MS1L8

West, K. (2017) Carmakers' Electric Dreams Depend on Supplies of Rare Minerals. Retrieved from https://www.theguardian.com/environment/2017/jul/29/electriccars-battery-manufacturing-cobalt-mining.

Zablocki, A. (2019). Fact Sheet: Energy Storage. Environmental and Energy Study Institute. Retrieved from https://www.eesi.org/papers/view/energy-storage-2019 